\title{
NOTE
}

\section{Taura syndrome in Pacific white shrimp Penaeus vannamei cultured in Taiwan}

\author{
Chien Tu ${ }^{1, *}$, Hsu-Tien Huang ${ }^{3}$, Sheng-Hsiung Chuang ${ }^{3}$, Jung-Ping Hsu ${ }^{3}$, Shu-Ting Kuo ${ }^{2}$, \\ Nan-Jung $\mathrm{Li}^{1}$, Tien-Lai Hsu ${ }^{2}$, Ming-Chang $\mathrm{Li}^{4}$, Shih-Yuh Lin $^{2}$ \\ ${ }^{1}$ Department of Biological Research and ${ }^{2}$ Department of Epizootic Research, Taiwan Animal Research Institute, Tansui 251, Taiwan, ROC \\ ${ }^{3}$ Pingtung Livestock Disease Control Center, 110-1 Shui-Yuan Sec., Pingtung 900, Taiwan, ROC \\ ${ }^{4}$ Pig Research Institute Taiwan, PO Box 23, Chunan, 35099, Miali, Taiwan, ROC
}

\begin{abstract}
Mass mortality of cultured white shrimp in southern Taiwan was diagnosed as an outbreak of Taura syndrome (TS). From late 1998 to early 1999, 90\% of the shrimp ponds were abandoned at 30 to $45 \mathrm{~d}$ after stocking post larvae from Ecuador and elsewhere. The shrimp began to die within 2 to $3 \mathrm{~d}$ after they stopped feeding. There were no other gross signs, except that some affected shrimp had reddened tails. Histologically, multifocal necrosis of the cuticular epithelium was the main lesion. The necrotic foci contained pyknotic and karyorrhectic nuclei, and many lightly and densely stained intracytoplasmic and intercellular, spherical inclusions. By transmission electron microscopy, small, icosahedral, picornalike virus particles $30 \mathrm{~nm}$ in diameter were seen. Taken together, the observations resembled those for outbreaks caused by Taura syndrome virus (TSV). It is assumed that TSV was transferred to Taiwan via contaminated post larvae and spawners from epizootic areas. This is the first report of a TS outbreak in Taiwan.
\end{abstract}

KEY WORDS: Penaeus vannamei - Taura syndrome - Viral disease $\cdot$ Penaeid shrimp

Taura Syndrome (TS) was first reported in 1992 for shrimp farmed near the mouth of the Taura river in Ecuador (Jimenez 1992). It quickly spread to the USA (Hawaii, Texas and Florida; Lightner 1996), South Carolina (Anonymous 1996), and to other countries in South and Central America, including Peru, Honduras, Guatemala, El Salvador, Brazil, Nicaragua, Belize, and Mexico (Sinaloa, Chiapas, Gueerrero) (Lightner 1996). Penaeus vannamei is highly sensitive to TS (Lightner 1996).

When first introduced to Taiwan, Penaeus vannamei was not attractive to grass shrimp farmers. However, after the catastrophic losses caused by monodon baculovirus (MBV) in 1988 (Lightner et al. 1987, Chen et al. 1989) and white spot syndrome virus (WSSV) in 1993 (Lo \& Ko 1998), most farmers switched to raising

- Present address: National Institute for Animal Health, Council of Agriculture 376 Chung-Cheng Rd. Tansui 251, Taiwan, ROC.E-mail: ctu@dns.tahri.gov.tw this newly introduced species. By early 1998, $P$. vannamei became the most popular and highest-yield cultured shrimp in southern Taiwan. However, from late 1998 to early 1999, due to high mortality, shrimp production dropped sharply to as little as $10 \%$ of the production in early 1998.

Based on the gross signs of disease, histopathological changes and evidence from transmission electron microscopy, we report in this paper that Taura Syndrome Virus (TSV) was responsible for the high shrimp mortality.

Materials and methods. Moribund shrimp collected from cultivation ponds experiencing high mortality were fixed by Davison's fixative and processed as described in Bell \& Lightner (1988). For electron microscopy, whole moribund shrimp were mixed with 10 -fold phosphate buffered saline, $\mathrm{pH} 7.2$, homogenized and centrifuged at $1000 \times g$ for $15 \mathrm{~min}$. The supernatant was centrifuged at $90000 \mathrm{rpm}(160000 \times \mathrm{g})$ for 10 min by Airfuge (Beckman) and stained with $1 \%$ phophotungstic acid for observation. For thin sections, samples were fixed in $2.5 \%$ phosphate buffered glutaraldehyde, pH 7.2 (0.1\% phosphate buffer), postfixed with $2 \% \mathrm{OsO}_{4}$, embedded in synthetic resin (Epon-812), sectioned and stained with uranyl acetate and lead citrate. All the electron microscopy was done using a Toshiba $\mathrm{H}-600$ at $75 \mathrm{kV}$.

Results. The affected shrimp showed gross signs of disease at 30 to $45 \mathrm{~d}$ after they were stocked in rearing ponds as post larvae. Moribund shrimp from 3 different shrimp ponds showed prominent expansion of red chromatophores in appendages (e.g. uropods, pereiopods, pleopods, and telsons), where necrotic foci were also sometimes found (Fig. 1). Most of the affected shrimp died within 2 to $3 \mathrm{~d}$ after losing their appetite for feed.

Multifocal necrosis was observed in the cuticular epithelium of the body surface, and especially in the reddened telson. The necrotic foci contained cellular 


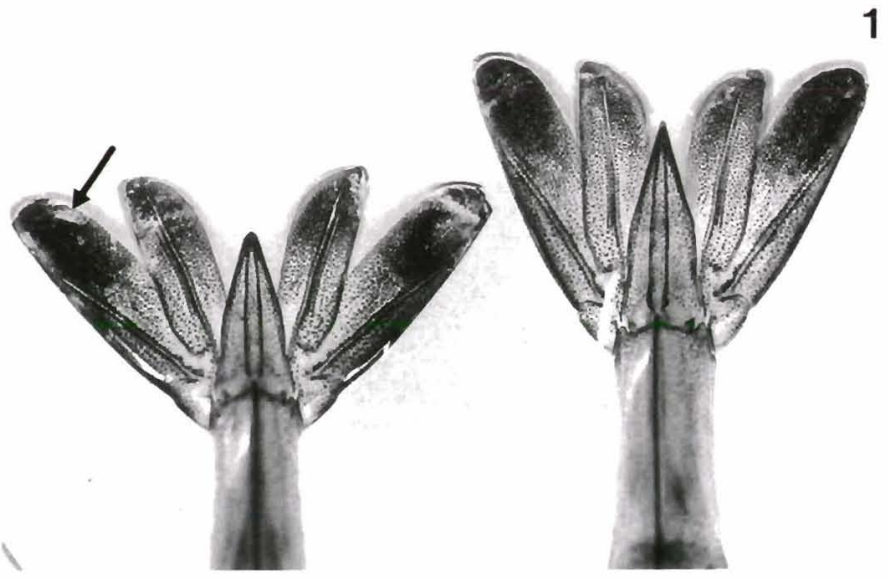

Fig. 1. Penaeus vannamei. TSV-infected shrimp with necrotic foci of reddish tail fan (arrow) diameter) parvovirus that forms intranuclear inclusions. The latter is a large baculovirus (380-250 $\mathrm{nm} \times 70-150 \mathrm{~nm})$ that causes characteristic hypertrophied nuclei. The sizes and cellular location of these viruses differ from those of TSV. A third Asian virus that targets the cuticular epithelium (among other tissues) is rod-shaped yellow-head virus (150-200 $\mathrm{nm} \times$ 40-50 $\mathrm{nm}$ ) that forms cytoplasmic inclusions (Boonyaratpalin et al. 1993). Although these inclusions are spherical and numerous, they are always basophilic and not amphophilic like those caused by TSV. None of the histological or ultrastructural features of these other viruses were seen in this study.

It is still unclear how TSV was introduced to Taiwan. Transport of TSV-contaminated frozen debris, pyknotic and karyorrhectic nuclei, and many lightly to densely stained, intracytoplasmic and intercellular inclusions (Fig. 2) that gave the lesion a 'buckshot' appearance (Lightner et al. 1995).

Virus particles $30 \mathrm{~nm}$ in diameter were seen in the supernatant from centrifuged tissue homogenates (Fig. 3). In thin sections, numerous virus particles were found in both electron-lucent and dense areas of the cytoplasm (Fig. 4). Needle-like crystals of calcium phosphate were also observed in affected cells (Fig. 5) (Lightner et al. 1995).

Discussion. Our results indicated that TSV was the cause of the disease outbreaks in white shrimp culture ponds in southern Taiwan. Three Asian shrimp viruses have tropism for the cuticular epithelium, as does TSV. Two such viruses, infectious hypodermal and haematopoietic necrosis virus (IHHNV; Lightner et al. 1987), and white spot syndrome virus (WSSV; Lo \& Kou 1998), have previously been reported from Taiwan. The former is a small $(22 \mathrm{~nm}$ in

Fig. 2. Penaeus vannamei. Histopathological changes with TS. The lesions contain many hypertrophied, pyknotic and karyorrhetic nuclei and intracytoplasmic and intercellular includion bodies (arrow). Scale bar $=22 \mu \mathrm{m}$

Fig. 3. Penaeus vannamei. Transmission electron photomicrograph showing negatively stained virus particles $30 \mathrm{~nm}$ in diameter (arrow). Scale bar $=100 \mathrm{~nm}$
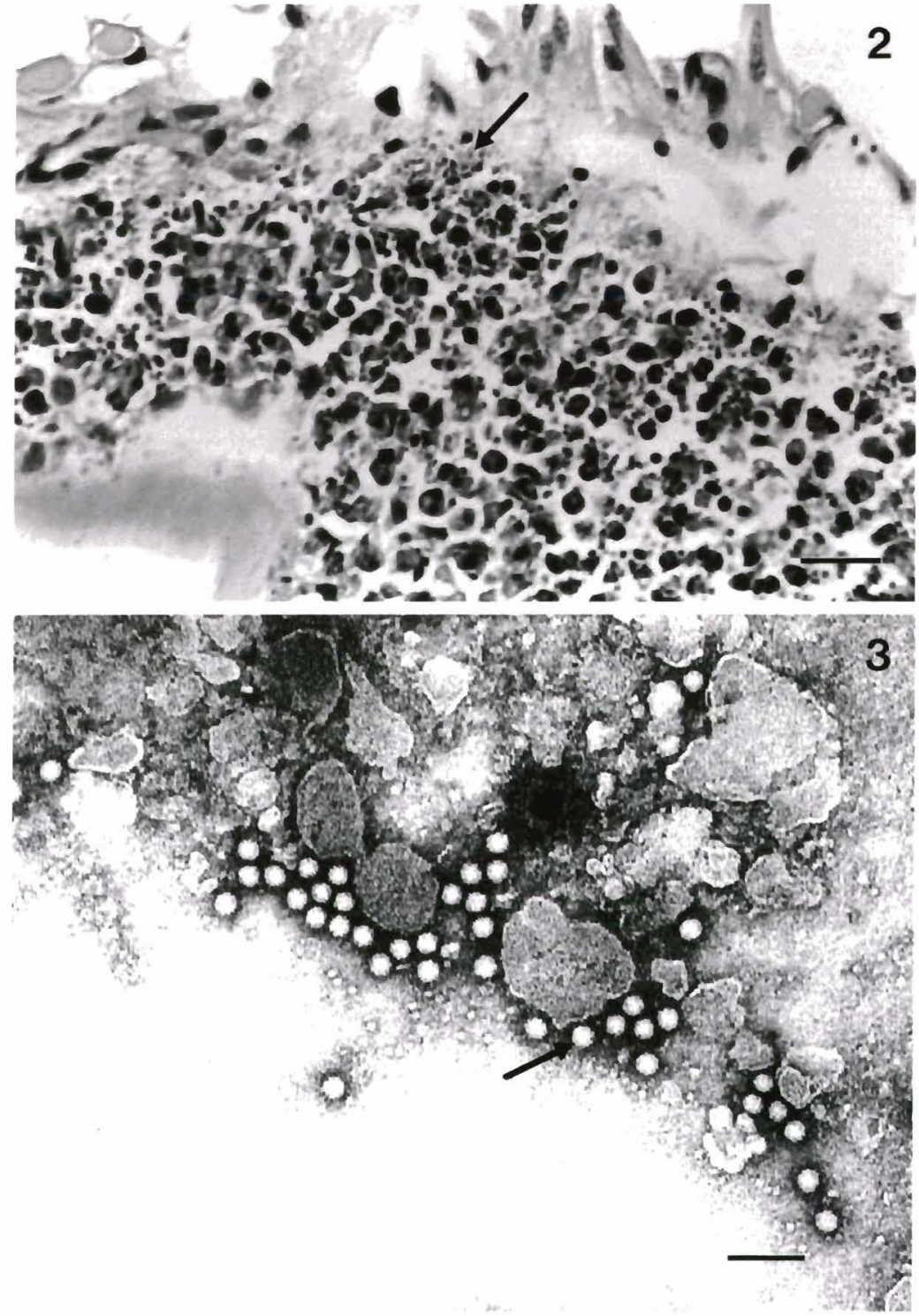
Fig. 4. Penaeus vannamei. Transmission electron photomicrograph showing virus particles (arrow) existing in the electronlucent and -dense areas of the inclusion bodies. Ultra-thin section. Scale bar $=$ $250 \mu \mathrm{m}$

Fig. 5. Penaeus vannamei. Transmission electron photomicrograph showing the needle-like crystals of calcium phosphate (arrow) in the affected cell. Ultra-thin section. Scale bar $=100 \mathrm{~nm}$

shrimp imported from other countries has been proposed as a possible mode for introduction of exotic shrimp viruses (Lightner et al. 1997). However, the main imported species in Taiwan are frozen grass shrimp Penaeus monodon and kuruma shrimp $P$. japonicus and they are not imported from areas endemic for TSV. P. vannamei imported from Hawaii began to be stocked in Taiwan in early $1998 ; 70$ to $80 \%$ of the farmers had good harvests. Then, in late 1998 and early 1999 , only $10 \%$ of the farmers successfully stocked the post larvae from Ecuador or post larvae hatched locally with spawners obtained from unknown sources (C.J. Wang pers. comm.). Thus, importation of TSV-contaminated $P$. vannamei post larvae or spawners was probably the main origin of the TSV outbreak in Taiwan.

Acknowledgements. We thank Chen-Chi Hsu for his histopathology technical assistance and Dr Po Chung for his critical review and correction of the manuscript. Special thanks to Dr Ivan-Chen Cheng and Dr HsinHsiung Hung for their assistance in this diagnosis.

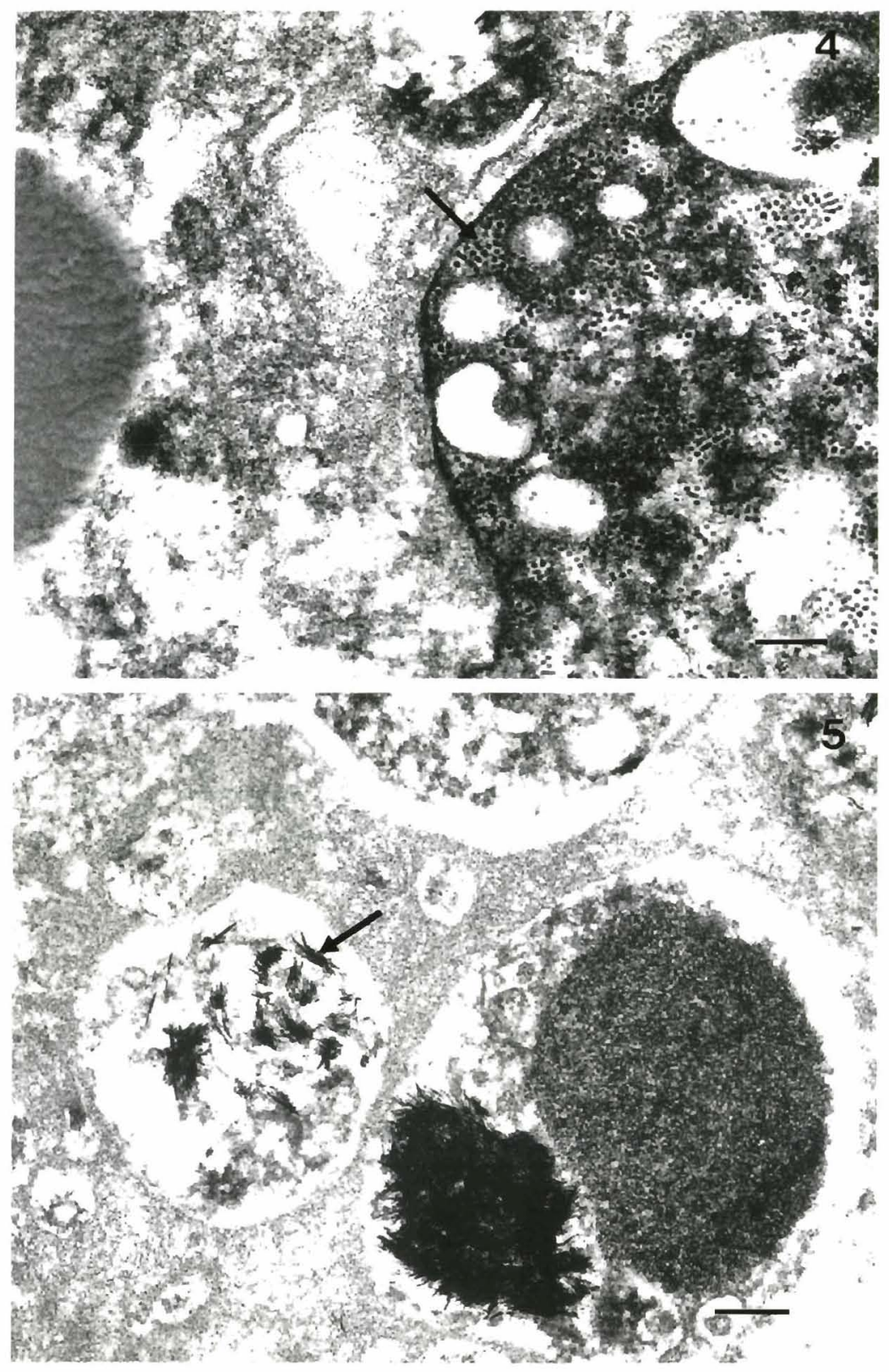

\section{LITERATURE CITED}

Anonymous (1996) Taura syndrome virus strikes South Carolina. American Fisheries Society, Introduced Fish Section Newsletter 15:2

Boonyaratpalin S, Supamattaya K, Kasornchandra J, Direkbusaracom S, Aekpanithanpon Chantanachooklin C (1993) Non-occluded baculo-like virus, the causative agent of yellow head disease in the black tiger shrimp (Penaeus monodon). Fish Pathol 28: 103-109

Chen SN, Chang PS, Kou GH (1989) Observation on pathogenicity and epizootiology of Penaeus monodon baculovirus (MBV) in cultured shrimp in Taiwan. Fish Pathol 24: $189-195$

Jimenez R (1992) Syndrome de Taura (Resumen). Acuacultura del Ecuador, Guayaquil 1:1-16

Lightner DV (1996) A handbook of shrimp pathology and diagnostic procedures for diseases of cultured penaeid shrimp. World Aquaculture Society, Baton Rouge, LA

Lightner DV, Hedrick RP, Fryer JL, Chen SN, Liao IC, Kou GH (1987) A survey of cultured penaeid shrimp in Taiwan for viral and other important diseases. Fish Pathol 22:127-140

Lightner DV, Redman RM, Hasson KW Pantoja CR (1995) Taura syndrome in Penaeus vannamei (Crustacea: Decapoda): gross signs, histopathology and ultrastructure. Dis Aquat Org 21:53-59

Lightner DV, Redman RM, Poulos BT, Nunan LM, Mart JL Hasson KW (1997) Risk of spread of penaeid shrimp viruses in the Americas by the international movement of live and frozen shrimp. Rev Sci Tech Off Int Epizoot 16: $146-160$

Lo CF, Kou GH (1998) Virus-associated white spot syndrome of shrimp in Taiwan: a review. Fish Pathol 33:365-371 